\section{Prevention of Post-operative Thrombosis}

SIR,-I should like to make comment on certain points in Mr. Hamilton Bailey's article (March 27, p. 594). In that article he emphasizes the importance of early detection of phlebothrombosis-importance which cannot be overstressed. He then proceeds to remark that the goal of prevention of phlebothrombosis cannot be reached at the present time save in a few clinics with special facilities. While perfection is a goal which is never reached in human circles, there can be no justification for the underlying suggestion that something very close to prevention of phlebothrombosis cannot be reached. I base my reasons for this statement on our observations in a Department of Health for Scotland Hospital at Ballochmyle, Ayrshire.

Towards the end of 1946 strenuous endeavours were commenced to institute a campaign in the surgical side of the hospital against post-operative phlebothrombosis and pulmonary embolism. The cases under treatment were general surgical, gynaecological, and ear, nose, and throat. In the first six months of that campaign our efforts were directed at instructing the junior medical staff, the nursing staff, and the physiotherapists in the early diagnosis of phlebothrombosis. Great endeavours were made to combat venous stasis by activity in bed, the abandoning of Fowler's position, increasingly early rising, and post-operative, breathing exercises. During this period 671 operations were performed. Eight of these patients were diagnosed as developing thrombosis and were treated with heparin and/or dicoumarin, and in none of them did a fatal embolism occur. There were five cases of sudden fatal pulmonary embolism in which phlebothrombosis had not been diagnosed previously.

In the following twelve months an impressive difference was seen. 1,622 operations were performed, with nine cases of phlebothrombosis and no fatal post-operative pulmonary embolisms. These cases were all treated with heparin, and in no case was venous ligation or thrombectomy carried out. "If these figures are compared with those quoted by Bauer (Lancet, 1946, 1, 447) with reference to the preanticoagulant era, we find that post-operative thrombosis occurred to one patient in every 180 , as against an expected rate of one in 60. Further, fatal pulmonary embolism occurred in no patients out of 1,622 , as against an expected rate of one in 360 . Perhaps this might be regarded as " an iota of evidence" that pulmonary embolism is less frequent in at least one hospital without special facilities than it was "ten, fifteen, or twenty years ago."

There can be no doubt that femoral thrombectomy is not called for save in a relatively advanced case of phlebothrombosis, and even in these cases satisfactory results accrue from heparinization. The risks of producing pulmonary embolisms during thrombectomy are surely considerably greater than the risks of fatal pulmonary embolism under adequate heparin therapy. One could hardly expect any better success than Bauer reports, namely three fatal pulmonary embolisms in 16,495 cases.

Mr. Bailey refers to the "unbridled use of expensive drugs." The average cost of treating a hospital patient with heparin for a recent and early phlebothrombosis is about $£ 14$. When prolonged morbidity or actual loss of life is being averted such a sum of money can scarcely be regarded as excessive even from a purely economic point of view. I am convinced that any surgical unit which is determined to reduce its rate of postoperative phlebothrombosis and pulmonary embolism can do so by adequate training within the unit and by the use of heparin when a case of phlebothrombosis is diagnosed.-I am, etc.,

Mauchline Ayrshire.

\section{Gavin J. Cleland.}

\section{Clinical Value of E.S.R.}

SIR,-Dr. J. Robertson Sinton's article (Feb. 28, p. 391) on the erythrocyte sedimentation rate was of great interest, but there are some points in his article to which I should like to draw attention. He mentions that the investigation was carried out at laboratory temperatures varying from $12^{\circ} \mathrm{C}$. to $25^{\circ} \mathrm{C}$. This is a wide range and surely tends to invalidate some of his figures. It has been shown by Westergren, ${ }^{1}$ Ham and Curtis, and others that a rise in temperature increases the rate of sedimentation; this, however, has been denied by Weingarten, who refutes the general statement that sedimentation rates are higher in warmer temperatures.

Table I shows readings taken simultaneously at $15.6^{\circ} \mathrm{C}$. $\left(60^{\circ} \mathrm{F}\right.$. $)$ and $21.1^{\circ} \mathrm{C}$. $\left(70^{\circ} \mathrm{F}\right.$. $)$ in a recent very small series of cases. It will be noted that the temperature range is smaller than that of Dr. Sinton's, and the differences would be greater still with his wider range. The method used was the standard Westergren with $200 \mathrm{~mm}$. tube, $1.6 \mathrm{ml}$. of blood, and $0.4 \mathrm{ml}$. of sodium citrate, and the readings were taken at the end of one hour.

TABLE I

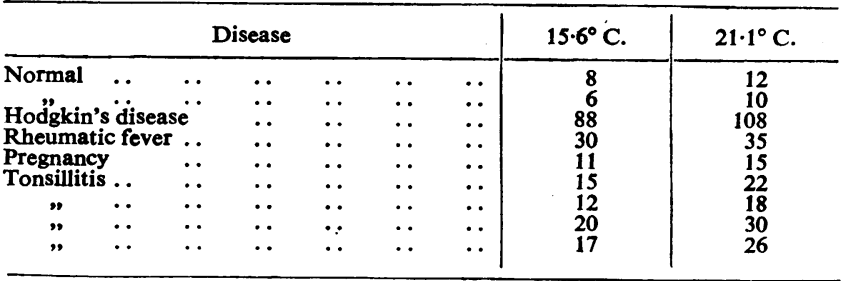

An additional possible inaccuracy in the Westergren technique using sodium citrate is the measurement of the latter and the blood. To show the difference between a $1: 4$ and $1: 3$ ratio of blood to sodium citrate a few sedimentation rates were carried out at a constant temperature using these two dilutions, and the results are shown in tabular form below.

TABLE II

\begin{tabular}{|c|c|c|c|c|c|c|}
\hline \multirow{2}{*}{\multicolumn{5}{|c|}{ Disease }} & \multicolumn{2}{|c|}{ Ratio of Blood to Sodium Citrate } \\
\hline & & & & & $1: 4$ & $1: 3$ \\
\hline Normal & .. & .. & .. & $\ldots$ & \multirow{7}{*}{$\begin{array}{l}8 \\
6 \\
30 \\
35 \\
13 \\
13 \\
32 \\
12 \\
16 \\
14\end{array}$} & \multirow{7}{*}{$\begin{array}{r}5 \\
4 \\
22 \\
24 \\
7 \\
10 \\
22 \\
8 \\
11 \\
9\end{array}$} \\
\hline Rheumatic fe & $\ddot{\text { ever }} \quad \because$ & $\because$. & $\therefore$ & $\because$ & & \\
\hline Pregnancy & $\because$. & $\therefore$ & $\therefore$ & $\because$. & & \\
\hline Tubëculous & $\ddot{\text { synovitis }}$ & $\because$ & $\because$ & $\because$ & & \\
\hline Tonsillitis & .. $\quad .$. & $\because$. & $\because$. & $\because$. & & \\
\hline 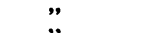 & . & .. & .. & . & & \\
\hline & 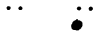 & .. & .. & $\cdots$ & & \\
\hline
\end{tabular}

An error of 0.1 to $0.2 \mathrm{ml}$. in measuring the blood or citrate may be sufficient to alter the ratio from $1: 4$ to $1: 3$ - such an error may easily arise with the type of syringe usually used.

A final factor influencing the rate is the inclination of the tube. Westergren, Wintrobe and Landsberg, ${ }^{4}$ Ponder, ${ }^{5}$ and others all emphasize the necessity for the tube to be vertical ; this is difficult to achieve. Moreover Ham and Curtis ${ }^{2}$ have shown that only $5^{\circ}$ from the vertical produces a substantial error. A method of ensuring a vertical tube and also a constant temperature is that advocated by Rogers. ${ }^{6}$ In this the tube forms its own plumb-line, is plugged at its lower end, and is suspended in a large jar containing water at the desired temperature. The method is rapid, and the results may be directly compared-this is especially important in serial cases where the sedimentation rate is used as a guide to progress and in which normally a winter reading might be too low and a summer reading too high. - I am, etc.,

$$
\text { London, S.W.3. }
$$

\section{C. JoSEPH.}

\section{REFERENCES}

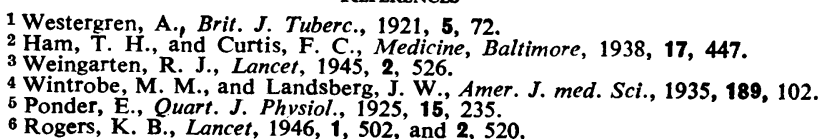

\section{Medicine in a Planned Economy}

SIR,- - Finding myself very much in agreement with the trend of thought in the article by Dr. Ff. Roberts (March 13, p. 485) I cannot help adding the plea to all doctors in hospital or practice to be more thoughtful in their selection of, and demand for, specialized tests and laboratory examinations.

A friend who works in a large hospital in this city, where the patients are largely drawn from the upper age limits of the population, commented acidly to me on this very point the other day. As he puts it : "Subjecting an aged (75) arteriosclerotic with cerebral thrombosis to a full blood examination, lumbar puncture, and other examinations " may be an exaggeration of the actual state of affairs, but there is no doubt that a lot of tests (useless so far as the future of the patients is concerned) are being done. The minds of the younger members 